\title{
Morfoestratigrafia do noroeste da planície costeira de São João de Pirabas (Nordeste do Pará)
}

\author{
(Morphostratigraphy of the northwestern São João de Pirabas coastal plain \\ (northeastern of Pará State))
}

\author{
Osmar Guedes da Silva Júnior ${ }^{1}$ \& Maâmar El-Robrini² \\ ${ }^{1}$ Laboratório de Computação Aplicada às Geociências - Universidade Federal do Pará \\ (Caixa Postal 1611,66075-110, Belém do Pará, PA, Brasil) \\ e-mail: guedesjr@ufpa.br \\ 2Laboratório de Oceanografia - Universidade Federal do Pará \\ (Caixa Postal 8617, 66075-110, Belém do Pará, PA, Brasil) \\ e-mail: robrini@ufpa.br
}

- Abstract: A sedimentary pattern, characterized by four marine successions, is identified at the northwestern portion of São João de Pirabas coastal plain (northeastern of Pará State) using morphostratigraphical analysis. The successions are: (i) basal retrogradational marine succession - SB, (intertidal mangrove muds, old beach ridges sand and tidal channel sand); retrogradational marine succession - S1, (sandy sediments of the shoreface); progradational succession - S2 (tidal flat and chêniers associated) and; actual retrogradational succession - S3 (dune-beach ridges, longitudinal sandy bars and bays, migrate over mangrove deposits). The evolution of this plain is related to sea-level changes associated with neotectonic movements since the Pliocene that gave origin to the SB succession during transgressive period related to Upper Pleistocene (?). The S1, S2, and $\mathrm{S} 3$ successions were developed due to transgressive and regressive cycles during last 5.100 years B.P. until today.

- Resumo: Na Planície Costeira de São João de Pirabas (NE do Pará), ocorrem principalmente depósitos terciários e quaternários, cuja distribuição e espessura foram influenciadas por movimentos neotectônicos e oscilações do nível do mar atuantes desde - Mioceno. A análise estratigráfica com base em testemunhos (com até $6 \mathrm{~m}$ de comprimento), permitiu a identificação de um padrão de sedimentação, visualizado através de quatro sucessões marinhas: sucessão marinha retrogradacional basal - SB (lamas de intermaré, areias de antigos cordões praiais e areias de canais de maré); sucessão marinha retrogradacional - S1 (sedimentos predominantemente arenosos de face praial); sucessão progradacional - S2 (ambiente de planície de maré e "cheniers" associados) e; sucessão retrogradacional atual - S3 (cordões duna-praia, barras arenosas longitudinais e de baías, que migram sobre os manguezais). A evolução desta planície está relacionada às oscilações do nível do mar que, inicialmente, deram origem a sucessão Retrogradacional Basal (SB), durante uma fase transgressiva relacionada ao Pleistoceno Terminal (?), enquanto as sucessões S1, S2 e S3 teriam evoluído a partir da atuação de ciclos transgressivos e regressivos, desde aproximadamente 5.100 anos A.P até os dias atuais.

- Descriptors: Coastal plain, Morphostratigraphy, Stratigraphics facies, Sea level.

- Descritores: Planície costeira, Morfoestratigrafia, Fácies estratigráficas, Nível do mar. 


\section{Introdução}

O conhecimento do quadro geológico do litoral do Nordeste do Estado do Pará é quase que totalmente voltado para as unidades terciárias, que afloram na faixa litorânea do Estado, mais especificamente a Formação Pirabas, datada do Mioceno Inferior (Maury, 1925; Ferreira \& Cunha, 1957, 1959; Ferreira, 1980), e Grupo Barreiras (MioPlioceno, Francisco et al., 1971; Arai et al., 1988).

Os depósitos quaternários recobrem a maior parte do NE do Pará e permaneceram quase que totalmente desconhecidos até as décadas passadas. A partir dos anos 80/90, deu-se início à pesquisas sobre os depósitos quaternários, onde destacam-se os trabalhos de Franzinelli ${ }^{1}$ (1982, 1990 e 1991); Faria Jr. et al. (1992); IDESP (1992); Sena et al. (1992); El-Robrini $^{2}$ (1993); El-Robrini \& Costa (1993); ElRobrini et al. (1992); Bemerguy et al. ${ }^{3}$ (1992), Pereira (1994) Souza Filho (1995), Silva (1996), Santos (1996), Silva (1998) e Silva Júnior (1998).

A região costeira do Município de São João de Pirabas, assim como todo o litoral do NE do Pará, é orientada segundo uma direção geral NW-SE e integra o litoral de "rias", cuja configuração evolutiva está relacionada aos episódios finais da Transgressão Holocênica (5.100 anos A. P.), que associada às características fisio-estruturais desta região, modelaram os traços essenciais da faixa costeira, onde as áreas abatidas deram origem as reentrâncias ("rias") e as áreas altas (falésias) originaram as saliências deste litoral (El-Robrini \& Costa, op.cit.).

Este artigo apresenta os resultados do estudo sobre a morfoestratigrafia do NW da Planície Costeira de São João de Pirabas, com base na análise de testemunhos e seções aflorantes, onde são discutidos a caracterização faciológica e estratigráfica dos depósitos quaternários, e a evolução destes, em resposta principalmente, às prováveis oscilações do nível do mar durante o Quaternário.

(1) Bemerguy, R. L.; Borges, M. S. \& Costa, J. B. S. 1992 Geomorfologia da região do Salgado, NE do Estado do Pará. In: CONGRESSO BRASILEIRO DE GEOLOGIA, 37. São Paulo, 1992. Resumos. São Paulo, SBG, 2:269.

(2) Franzinelli, E. 1991. Evolução e origem da costa atlântica do Estado do Pará. In: CONGRESSO DA ASSOCIAÇÃO BRASILEIRA DE ESTUDOS DO QUATERNÁRIO, 3. Belo Horizonte, 1991. Resumos. Belo Horizonte, ABEQUA. p. $117-118$

(3) El-Robrini, M.; Faria Jr., L. E. C.; Souza Filho, P. W. M. \& Silva, M. S. 1992. Deposição e assoreamento dos rios do nordeste do Estado do Pará. In: CONGRESSO BRASILEIRO DE GEOLOGIA, 37. São Paulo, 1992. Resumos. São Paulo, SBG, $1: 79-80$

\section{Material e métodos}

As atividades constaram da confecção de uma base cartográfica, onde foram utilizadas: (i) fotografias aéreas convencionais em escala 1:70.000 (1978) da Companhia de Pesquisas e Recursos Minerais (CPRM), (ii) imagens de satélite LANDSAT TM-5, referente ao quadrante D da órbita ponto $223 / 60$ da passagem de $23 / 07 / 88$, fornecidas pelo Centro de Hidroclimatologia e Sensoriamento Remoto da Amazônia (CHSRA/SUDAM), e (iii) carta planialtimétrica (Folha Salinópolis SA-23-V-AV) na escala de 1:100.000.

De posse da base cartográfica, foram elaborados transectos dispostos perpendicularmente a linha de costa, ao longo dos quais foram coletados 26 testemunhos (do tipo "Vibracorer"), cujas localizações foram feitas mediante o Sistema de Posicionamento Global (GPS). A posição altimétrica dos testemunhos foi uma aproximação feita em campo, com base no nível de maré alta, em virtude de não existir nenhum DATUM e nem carta topográfica da área.

A metodologia aplicada no processamento das amostras, consistiu de estudos que envolveram análises granulométricas e morfométricas. Os testemunhos foram processados e analisados a partir de descrições macroscópicas detalhadas e interpretações de suas fotografias.

\section{Aspectos regionais}

A região estudada ocupa a porção $\mathrm{NW}$ da Planície Costeira do Município de São João de Pirabas, localizada entre os paralelos $00^{\circ} 37^{\prime} 20^{\prime \prime} \mathrm{e}$ $00^{\circ} 43^{\prime} 57^{\prime \prime}$ de latitude sul e $47^{\circ} 16^{\prime} 34^{\prime \prime}$ e $47^{\circ} 11^{\prime} 49^{\prime \prime} \mathrm{W}$ Gr, segundo a Folha SA - 23-V-A-V (Salinópolis), abrangendo uma área com cerca de $91 \mathrm{~km}^{2}$ (Fig. 1). Ocorrem principalmente depósitos calcários da Formação Pirabas, que afloram localmente, sedimentos areno-síltico-argilosos do Grupo Barreiras; e areno-argilosos do pós-Barreiras, os quais compõem falésias ativas $\mathrm{e}$ inativas, além dos depósitos holocênicos que formam as praias, planícies de maré, dunas, barras, cordões arenosos ("cheniers") e manguezais (Franzinelli, 1982; Sena et al., 1992).

Silva Júnior (1998) reconheceu, com base em dados morfológicos e critérios morfogenéticos, duas unidades morfológicas distintas: (i) Planalto Costeiro e (ii) Planície Costeira (Fig. 1).

O Planalto Costeiro ocorre no sul da área e restritamente no sudeste da Ilha de Itarana. Consiste em um relevo colinoso, suavemente ondulado, com altitude em torno de $30 \mathrm{~m}$, sustentado pelos 


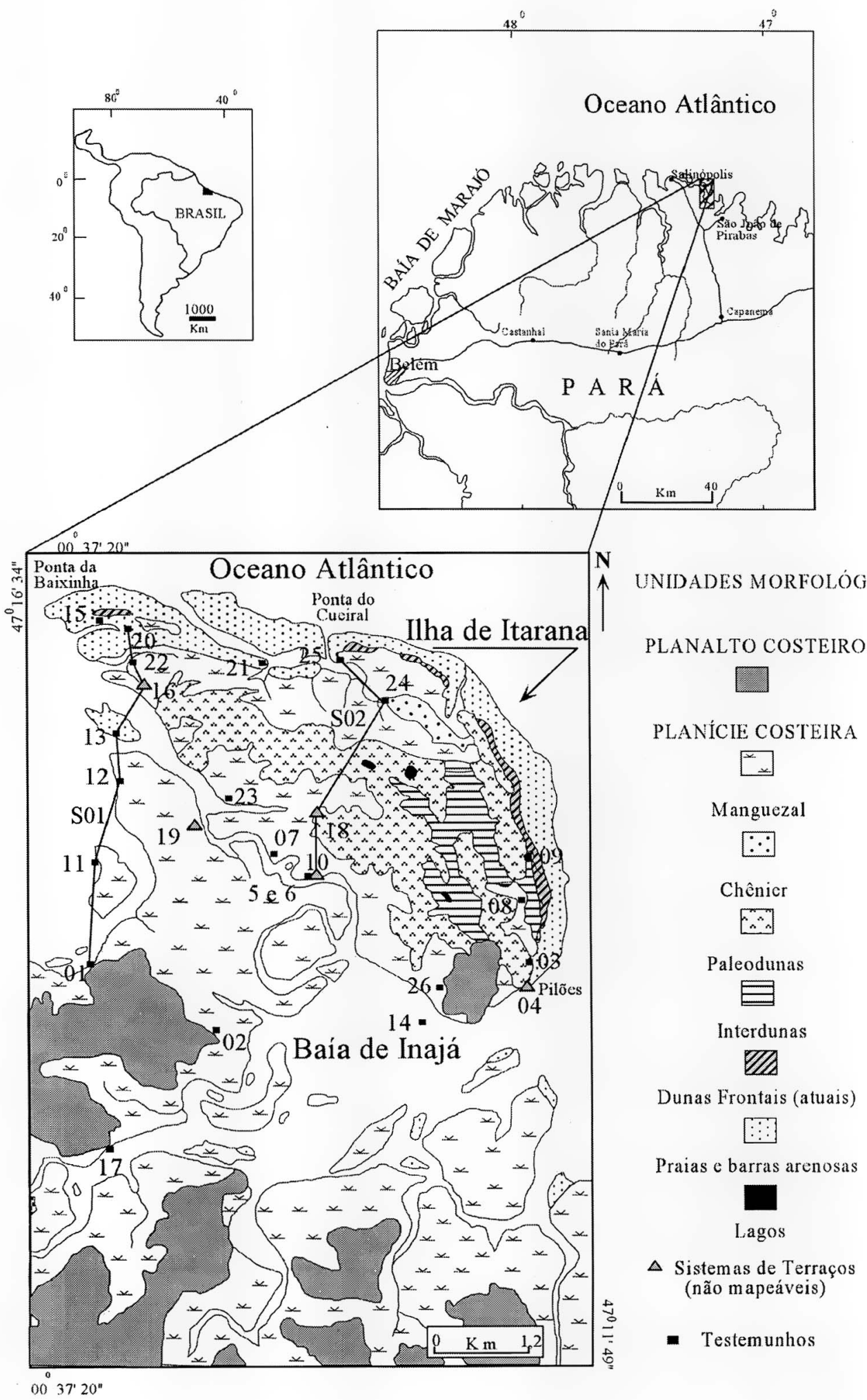

Fig. 1. Mapa de localização da área estudada, mostrando as unidades morfológicas e a localização dos testemunhos e seções estratigráficas S01 e S02. 
sedimentos do Grupo Barreiras e pós-Barreiras. A Planície Costeira está representada por ambientes de manguezais de intermaré, sistema de terraços, "cheniers", paleodunas, interdunas, lagos, dunas frontais (atuais), praias e barras arenosas.

A região é influenciada por um clima tropical quente e úmido do tipo Am2, de acordo com a classificação de Köppen, adaptada por Martorano et al. (1993). Caracteriza-se por apresentar um período chuvoso bem acentuado nos meses de dezembro a maio, e uma estação menos chuvosa de junho a novembro, com uma precipitação pluviométrica média anual variando de 2500 a $3000 \mathrm{~mm}$ e umidade relativa do ar que oscila entre 80 e $90 \%$ anualmente.

Fisiograficamente, a região integra as Reentrâncias do NE do Pará e NW do Maranhão, sendo recortada por baías estuarinas, dominadas por um regime de macro-marés, semi-diurnas, com amplitude máxima em torno de $5,7 \mathrm{~m}$, onde a amplitude média das marés de sizígia é de $4,9 \mathrm{~m}$ e a amplitude média das marés de quadratura é de $2,8 \mathrm{~m}$ (DHN, 1998).

As principais correntes que atuam na região são as correntes de maré, relacionadas à variação das marés, que atingem velocidades máximas de 2,1 nós ( $6 \mathrm{~h}$ antes da preamar nas marés de sizígia) e mínima de 1,9 nós $(4 \mathrm{~h}$ depois da preamar nas marés de quadratura), com direções E-NW e NE (DHN, 1986); e correntes litorâneas, resultantes da chegada de 'ondas à costa, geradas pela ação dos ventos alísios de direção E-NE, com velocidades médias de $7,9 \mathrm{~m} / \mathrm{s}$ predominantes nos meses de dezembro a maio. Durante os meses de junho a novembro, os ventos predominam na direção leste, com intensidades em torno de $7 \mathrm{~m} / \mathrm{s}$ (DHN, 1986).

\section{Resultados}

\section{Morfoestratigrafia}

$\mathrm{Na}$ caracterização estratigráfica, foi adotado o conceito de unidade morfoestratigráfica, aplicado primeiramente por Frey \& Milliman (1960) no mapeamento de depósitos glaciais pleistocênicos do Lago Michigan nos Estados Unidos, bem como o conceito de fácies estratigráficas. Estes princípios tem sido amplamente utilizados na Planície Costeira da Austrália, por Rhodes (1982), Woodroffe et al. (1986, 1989) dentre outros. No NE do Pará, a aplicação destes conceitos foi primeiramente realizada por Souza Filho (1995) na Planície Costeira Bragantina e seguida por Silva (1996) e Santos (1996), no estudo das Planícies Costeiras de Salinópolis e Algodoal/ Marudá, respectivamente.

Foram individualizadas oito unidades morfoestratigráficas e oito fácies estratigráficas (Tabs 1 e 2), caracterizadas a partir da análise de 26 testemunhos (Fig. 1) e da exposição de corpos sedimentares.

Tabela 1. Unidades morfoestratigráficas identificadas no NW da Planície Costeira de São João de Pirabas.

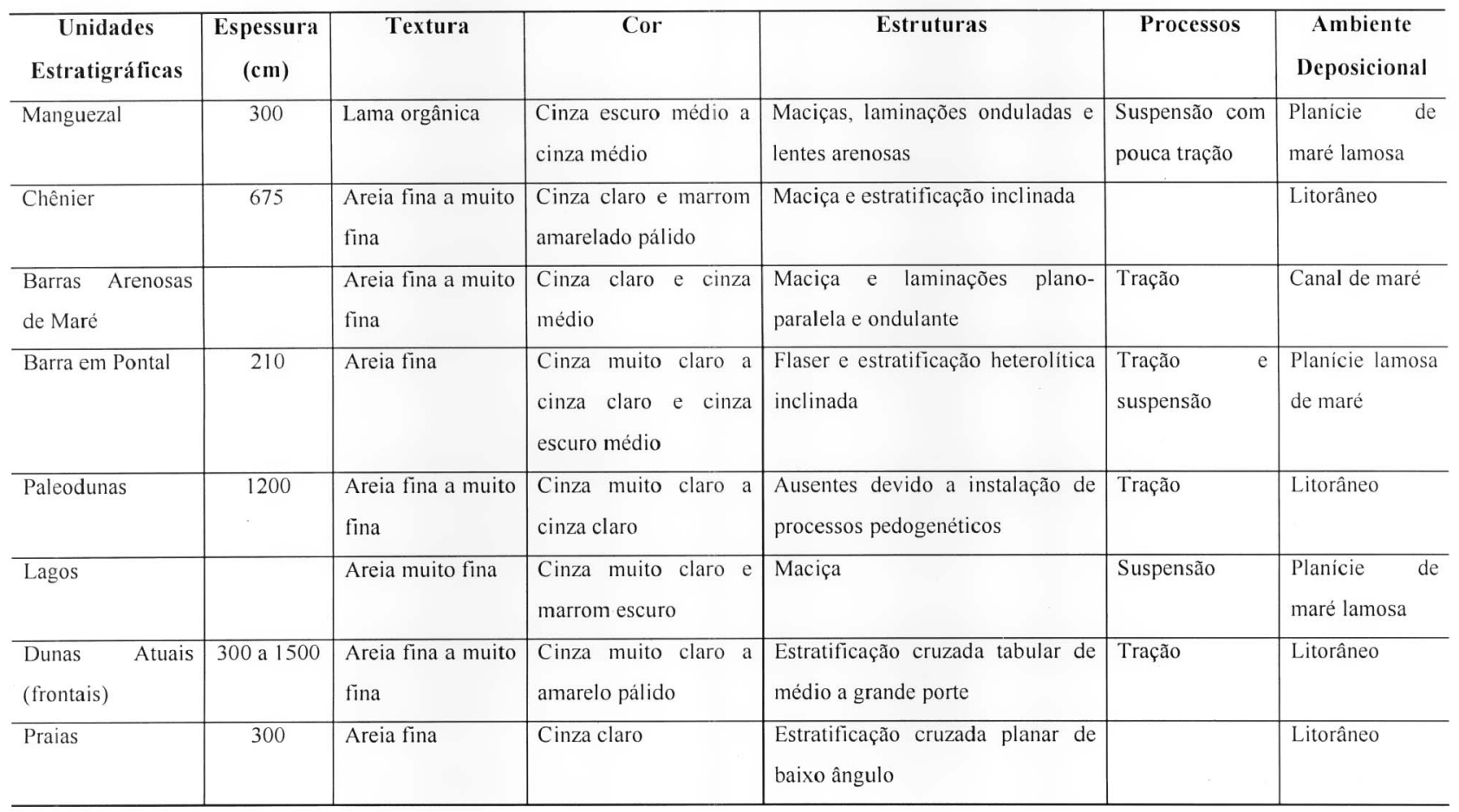


Tabela 2. Fácies estratigráficas identificadas no NW da planície costeira de São João de Pirabas.

\begin{tabular}{|c|c|c|c|c|c|c|}
\hline $\begin{array}{c}\text { Fácies } \\
\text { Estratigráficas }\end{array}$ & $\begin{array}{l}\text { Espessu } \\
\text { ra }(\mathrm{cm})\end{array}$ & Textura & Cor & Estruturas & Processos & $\begin{array}{c}\text { Ambiente } \\
\text { Deposicional }\end{array}$ \\
\hline Areia Marinha & $\begin{array}{c}120 a \\
210\end{array}$ & $\begin{array}{l}\text { Areia fina a muito } \\
\text { fina }\end{array}$ & $\begin{array}{l}\text { Cinza muito claro a } \\
\text { claro }\end{array}$ & $\begin{array}{l}\text { Estratificações plano-paralela e } \\
\text { cruzada de baixo ângulo }\end{array}$ & & $\begin{array}{l}\text { Face praial } \\
\text { (shoreface) }\end{array}$ \\
\hline $\begin{array}{l}\text { Areia e Lama } \\
\text { Marinha/Estuarina }\end{array}$ & 30 a 200 & $\begin{array}{l}\text { Areia fina a muito } \\
\text { fina }\end{array}$ & $\begin{array}{l}\text { Cinza muito claro e } \\
\text { cinza oliva }\end{array}$ & $\begin{array}{l}\text { Maciça, marcas onduladas, } \\
\text { acamamento de maré e flaser }\end{array}$ & & $\begin{array}{l}\text { Face praial } \\
\text { (shoreface) }\end{array}$ \\
\hline $\begin{array}{l}\text { Areia e Lama de } \\
\text { Barra em Pontal }\end{array}$ & 70 & $\begin{array}{l}\text { Areia fina a muito } \\
\text { fina intercalada } \\
\text { com argila }\end{array}$ & $\begin{array}{l}\text { Cinza muito claro e } \\
\text { cinza médio }\end{array}$ & $\begin{array}{ll}\text { Estratificação } & \text { hetetolítica } \\
\text { inclinada } & \end{array}$ & & Canal de maré \\
\hline $\begin{array}{l}\text { Areia de Canal de } \\
\text { Maré }\end{array}$ & $\begin{array}{c}300 \mathrm{a} \\
410\end{array}$ & $\begin{array}{l}\text { Areia fina e média } \\
\text { intercalada com } \\
\text { areia grossa }\end{array}$ & $\begin{array}{l}\text { Cinza muito a cinza } \\
\text { amarelado }\end{array}$ & $\begin{array}{l}\text { Estratificação cruzada tabular e } \\
\text { acanalada }\end{array}$ & & $\begin{array}{l}\text { Fundo de } \\
\text { canal de maré }\end{array}$ \\
\hline $\begin{array}{l}\text { Areia de Cordões } \\
\text { Praiais }\end{array}$ & 800 & $\begin{array}{l}\text { Silte, areia muito } \\
\text { fina a fina }\end{array}$ & $\begin{array}{l}\text { cinza claro na base e } \\
\text { marrom escuro no } \\
\text { topo }\end{array}$ & $\begin{array}{l}\text { Maciça, estratificações } \text { plano- } \\
\text { paralela, cruzada de baixo } \\
\text { ângulo, flaser, acamento } \\
\text { ondulado, lenticular e } \\
\text { laminações plano-paralelas }\end{array}$ & & Face praial \\
\hline Lama de Intermaré & 60 a 330 & Argila & $\begin{array}{l}\text { Cinza claro e cinza } \\
\text { escuro }\end{array}$ & Acamamento lenticular & & $\begin{array}{l}\text { Planície de } \\
\text { maré lamosa }\end{array}$ \\
\hline $\begin{array}{l}\text { Sedimentos Argilo- } \\
\text { Arenosos }\end{array}$ & 300 & Argila e areia & $\begin{array}{l}\text { Cinza claro com } \\
\text { manchas amarelas e } \\
\text { marrom claro }\end{array}$ & Maciça & & $\begin{array}{l}\text { Planície de } \\
\text { maré }\end{array}$ \\
\hline $\begin{array}{l}\text { Sedimentos } \\
\text { Carbonáticos }\end{array}$ & 60 & & $\begin{array}{lr}\text { Cinza } & \text { claro } \\
\text { manchas } & \text { marrom } \\
\text { escuro e } & \text { marrom } \\
\text { amarelado } & \end{array}$ & Maciça & & Plataformal \\
\hline
\end{tabular}

As unidades morfoestratigráficas foram definidas a partir de sua geometria de superfície e subsuperfície, além das suas propriedades sedimentológicas, referindo-se assim, aos ambientes atuais. As fácies estratigráficas foram definidas a partir das características texturais dos corpos sedimentares em subsuperfície.

\section{Unidades morfoestratigráficas}

\section{Unidade manguezal}

É a unidade de maior ocorrência na Planície Costeira, com uma área de $33,6 \mathrm{~km}^{2}$ e uma espessura máxima de $3 \mathrm{~m}$. Está representada por terrenos baixos quase horizontais constituídos por sedimentos lamosos ricos em matéria orgânica com intensa bioturbação que estão sob influência das marés e se desenvolvem ao longo das baías estuarinas, sendo recortados por canais e córregos de marés. Apresentam coloração cinza escuro médio (N4) a cinza médio (N5), onde os intervalos iniciais (até 20 $\mathrm{cm}$ ) possuem manchas marrom moderado (5YR 4/4) e intensa bioturbação, contendo restos e marcas de raízes. Apresentam-se maciços (sem estruturação aparente), contendo concentrações granulares de matéria orgânica de dimensões milimétricas dispersas nestes sedimentos. Em profundidade (de $105 \mathrm{~cm}$ até $150 \mathrm{~cm}$ ), são observadas laminações contínuas e descontínuas, onduladas, bem como, lentes de areia fina a muito fina de coloração cinza claro médio (N6), típicas de planície de intermaré lamosa. A cobertura vegetacional é composta por Rhyzophora mangle, Avicenia germinas e Laguncularia racenosa, 
estas com porte arbóreo e como vegetação herbácea encontra-se a Spartina sp. (gramínea).

Segundo Schaeffer-Novelli (1989), essas formações estão associadas a costas de baixa energia ou a ambientes estuarinos, lagunares, baías e enseadas que fornecem a proteção necessária ao seu estabelecimento, caracterizando uma zona de transição entre os ambientes oceânico e terrestre.

\section{Unidade "Chenier"}

Os cheniers são corpos arenosos (cordões de praia e de duna-praia) que repousam sobre depósitos lamosos de manguezais, isolados dos processos costeiros por uma planície lamosa subseqüente, implicando geneticamente, que a progradação da planície lamosa foi interrompida pela formação do chenier (Otvos \& Price, 1979 apud Augustinus, 1989).

$\mathrm{Na}$ área estudada, foram verificadas duas ocorrências destes corpos, que ocupam uma área de aproximadamente $0,64 \mathrm{~km}^{2}$. Possuem altura que não ultrapassa os $2 \mathrm{~m}$ e são colonizados por vegetação do tipo arbustivo. O primeiro desses corpos ocorre na localidade de Ponta da Baixinha, possui forma alongada na direção E-W com $1000 \mathrm{~m}$ de extensão e $170 \mathrm{~m}$ de largura máxima. Ressalta-se neste corpo a ocorrência de restos de vegetação de mangue, sendo que alguns ainda estão em posição de vida. O segundo corpo arenoso localiza-se na Ponta do Cueiral, próximo ao furo homônimo e possui forma alongada na direção NW-SE, com cerca de $1250 \mathrm{~m}$ de extensão e $380 \mathrm{~m}$ de largura máxima (Fig. 1).

Em subsuperfície, esta unidade está representada por um pacote arenoso com espessura máxima de $4,75 \mathrm{~m}$, recobertos por depósitos dunares de $2 \mathrm{~m}$ de espessura, muito finos de coloração cinza claro médio (N6). No intervalo inicial $(0-50 \mathrm{~cm})$, ocorrem sedimentos arenosos, quartzosos com grãos subangulosos finos a muito finos e bem selecionados, de coloração cinza claro (N7), que grada em profundidade para marrom amarelado pálido (10 YR $6 / 2$ ) com tonalidade marrom claro (5 YR 5/6). No topo, estes sedimentos são maciços $(0-20 \mathrm{~cm})$, passando em profundidade para uma estratificação inclinada, definida pela alternância de camadas milimétricas de areia fina e concentrações de matéria orgânica e/ou silte de coloração marrom escuro (5 YR $2 / 2$ ). Estes sedimentos correspondem a porção distal de leques de lavagem e são semelhantes aos descritos por Souza Filho (1995) nos "cheniers" da Planície Costeira Bragantina.

O intervalo subseqüente $(50-160 \mathrm{~cm})$ é caracterizado por sedimentos lamosos de coloração cinza médio (N4), cujo contato superior com a seqüência arenosa é representado por uma discordância erosiva, marcada por perfurações preenchidas com areias finas, e clastos argilosos imersos na seqüência superior. $\mathrm{Na}$ base desses sedimentos (160 a $475 \mathrm{~cm}$ ), ocorrem as fácies estratigráficas areia e lama marinha/estuarina e areias marinhas, que serão descritas posteriormente (Fig. 2B).

\section{Unidade barras arenosas de maré}

Esta unidade está representada por barras longitudinais desenvolvidas, principalmente na foz de canais de maré e de baias que formam, durante a maré baixa, uma extensa planície arenosa com cerca de $3,6 \mathrm{~km}^{2}$ de área. Ocorrem como corpos alongados, dispostos de forma paralela ou perpendicular à linha de costa, onde se desenvolvem ondulações, megaondulações e sistemas de cristas e calhas. Em alguns casos, migram sobre os manguezais, causando o seu soterramento. São constituídas por areias finas a muito finas, angulosas, bem selecionadas de coloração cinza claro (N7), contendo manchas cinza médio (N5) e laranja acinzentado (10YR 7/4). Apresentam-se maciças e com laminações planoparalela e ondulante, com restos de matéria orgânica e lentes lamosas associadas.

\section{Unidade Barras em Pontal}

Esta unidade atinge uma espessura máxima em torno de $210 \mathrm{~cm}$ e está associada aos canais de maré lamosos. Corresponde à níveis de areia fina, bem selecionada, de coloração cinza muito claro (N8) a cinza claro (N7) de até $10 \mathrm{~cm}$ de espessura, com estruturas flaser, e restos de matéria orgânica e fragmentos de conchas associados. Estes sedimentos arenosos estão intercalados a estratos lamosos de até $15 \mathrm{~cm}$ de espessura, de coloração cinza escuro médio (N4), com lentes e níveis de areia muito fina e/ou silte de coloração cinza claro (N7). Em trechos desta seqüência, os estratos possuem uma inclinação de 10 a $20^{\circ}$, definindo a estratificação heterolítica inclinada, estrutura esta, típica de barras em pontal (Fig. 2A).

\section{Unidade paleodunas}

Estão localizadas nas porções NW e SE da Ilha de Itarana (Fig. 1) e ocupam uma área de 8,3 $\mathrm{km}^{2}$. Ocorrem sob forma de extensos campos arenosos com alturas que variam desde os $2 \mathrm{~m}$ (SE da ilha de Itarana), até $12 \mathrm{~m}$ (porção $\mathrm{NW}$ e central da ilha). São limitadas pela planície de maré lamosa a NW, por interdunas a leste e pelo Planalto Costeiro a sul. Essa subunidade é colonizada por espécies arbóreas, arbustivas e cipós, alcançando, por vezes uma vegetação exuberante e diversificada com o 
porte de Mata. Na porção NW, próximo ao Furo Grande, as paleodunas estão degradadas e alcançam o referido furo como uma superfície plana arenosa. Apresentam-se compostas por areia fina a muito fina, muito bem selecionada, de coloração cinza muito claro (N8), onde não são observadas estruturas primárias preservadas, em função da instalação de processos pedogenéticos e intensa cobertura vegetal.

\section{Unidade lagos}

Ocorre associada aos campos de paleodunas (mais expressivos) e campos de dunas frontais (atuais). São alimentados principalmente por águas pluviais, secando parcialmente durante a estação chuvosa, que vai de junho a novembro. Caracterizam-se por depósitos arenosos muito finos, maciços cinza muito claro (N8), contendo restos de raízes e níveis de concentração de minerais pesados. Em profundidade, adquirem uma coloração marrom escuro e são ricos em matéria orgânica.

\section{Unidade dunas frontais (Atuais)}

Ocorrem na Ilha de Itarana desde a porção NW (Ponta da Baixinha), onde possuem pouca expressão areal, até o extremo sudeste da Ilha de Itarana, ocupando uma área de $0,45 \mathrm{~km}^{2}$ aproximadamente. Estão situadas logo após o póspraia e possuem direção geral E-W que inflete para $\mathrm{N}-\mathrm{S}$, constituíndo-se em cristas paralelas à linha de costa, formadas a partir do retrabalhamento dos sedimentos, provenientes das praias e barras prélitoral. Predominam dunas longitudinais fixadas por vegetação arbustiva, com alturas que variam de $3 \mathrm{~m}$ na Ponta da Baixinha, até $15 \mathrm{~m}$ na Ponta do Cueiral. São compostas por areias finas a muito finas, muito bem selecionadas de coloração cinza muito claro (N8) a amarelo pálido, com estratificação cruzada tabular de médio a grande porte.

\section{Unidade praias}

As praias compreendem toda a porção norte e sudeste da Ilha de Itarana, apresentando morfologia básica de praias planas (perfil geralmente retilíneo) e convexas, com ligeira inclinação em direção ao mar. Estão dispostas concordantemente à linha de costa e à foz das baías, com terminações recurvadas (spits), como verificado na Ponta da Baixinha. São compostas por areias quartzosas, finas, bem selecionadas, angulosas de coloração cinza claro (N7), com espessura de $3 \mathrm{~m}$, contendo estratificação cruzada planar de baixo ângulo, característica de fácies de praia.

\section{Fácies estratigáficas}

\section{Fácies areia e lama marinha/estuarina}

Esta fácies está distribuída sob as unidades morfoestratigráficas manguezal (T-07, T-14 e T-23) e barras arenosas de maré (T-14) a uma profundidade que varia de 30 a $200 \mathrm{~cm}$. É representada por depósitos arenosos quartzosos, finos a muito finos, angulosos, bem selecionados de coloração cinza claro (N7) a cinza muito claro (N8), maciços e com marcas onduladas. Intercalados a estes depósitos, ocorrem níveis e finas camadas de lama (no máximo $0,5 \mathrm{~cm}$ ) de coloração cinza oliva (5Y 4/1), que constituem acamamentos de maré e flaser, onde também são observados fragmentos vegetais (Fig. 2C).

\section{Fácies areia marinha}

Esta fácies ocorre sob a unidade morfoestratigráfica manguezal (T-15, T-20, T-21, T$22, \mathrm{~T}-24$ e T-25) a uma profundidade que varia de 120 a $210 \mathrm{~cm}$. Corresponde a areias quartzosas, finas a muito finas, subangulosas, bem selecionadas, de coloração cinza muito claro (N8) a cinza claro (N7), com fragmentos de conchas. Possuem estruturas maciças, plano paralelas e cruzadas de baixo ângulo, além de bioturbações preenchidas por lama de coloração cinza médio (N4), típicas de ambiente de face praial (Fig. 2D).

\section{Fácies areia de cordões praiais}

Ocorre sob as paleodunas e depósitos de manguezais, chegando até a superfície, formando um sistema de terraços e falésias ativas.

Nas margens da Baía do Inajá, localidade de Pilões, ocorre a melhor exposição desta fácies. Neste local, esta fácies alcança uma espessura máxima de 6 $\mathrm{m}$, formando uma falésia viva. $\mathrm{Na}$ base desta falésia, ocorre uma camada de coloração cinza claro médio (N6), friável, com aproximadamente $1 \mathrm{~m}$ de espessura, composta por areia fina, bem selecionada, intercalada com lâminas de material siltoso, definindo uma estratificação plano-paralela. $\mathrm{Na}$ porção intermediária, ocorre um pacote arenoso, fino, moderadamente selecionado, maciço (sem estruturas primárias visiveis) com $3,5 \mathrm{~m}$ de espessura de coloração creme e bastante bioturbado.

No topo, esta fácies apresenta-se bastante endurecida, sendo representada por uma camada de areia muito fina, bem selecionada de coloração marrom escuro (5YR 2/2) com 1,5 $\mathrm{m}$ de espessura, apresentando como estruturas primárias estratificação cruzada de baixo ângulo e lentes de material siltoarenoso. A coloração marrom escuro é função da 
concentração de ácidos húmicos $\mathrm{e}$ óxidos $\mathrm{e}$ hidróxidos de ferro que, provavelmente, favoreceu o endurecimento desta porção da fácies. Silva Júnior \& Soares (1992), em estudos realizados nesta fácies, descreveram em seção delgada, a presença de grãos de quartzo totalmente envoltos por uma película de óxi-hidróxidos de ferro, que de certa forma, levou a uma cimentação desta porção da fácies.

Em subsuperfície, esta fácies alcança uma espessura de $2 \mathrm{~m}$, ocorrendo geralmente sob os sedimentos da Unidade Morfoestratigráfica Manguezal, em profundidades que variam de 50 a $200 \mathrm{~cm}$ (T-05, T-06; T-08, T-10; T-16; T-18; T-19). Corresponde a sedimentos essencialmente arenosos, finos a muito finos, angulosos a subangulosos e, moderadamente a bem selecionados, de coloração marrom moderado (5YR 4/4) a marrom amarelado pálido (10YR 6/2). Intercalados a esses sedimentos, ocorrem lentes e lâminas (até $2 \mathrm{~cm}$ de espessura) silto-argilosas de coloração marrom escuro (5YR $2 / 2$ ), associadas com fragmentos de matéria orgânica, subarredondados que, por vezes, formam níveis de concentração com até $2 \mathrm{~cm}$ de espessura. Estas feições definem estruturas do tipo flaser, ondulada, lenticular e laminações plano-paralela (Figs. 2E e 2F).

\section{Fácies areia de canal de maré}

Ocorre sob a fácies Cordões Praiais (T-16 e T-19) a uma profundidade que varia de 300 a $410 \mathrm{~cm}$, sendo caracterizada por areias finas e médias, cinza muito claro (N8), com clastos de argila associados, intercalada com areia grossa angulosa a subangulosa, cinza amarelada (5Y 7/2). Esta intercalação define uma estratificação cruzada tabular no topo, que passa para acanalada, na base (Fig. 2E).

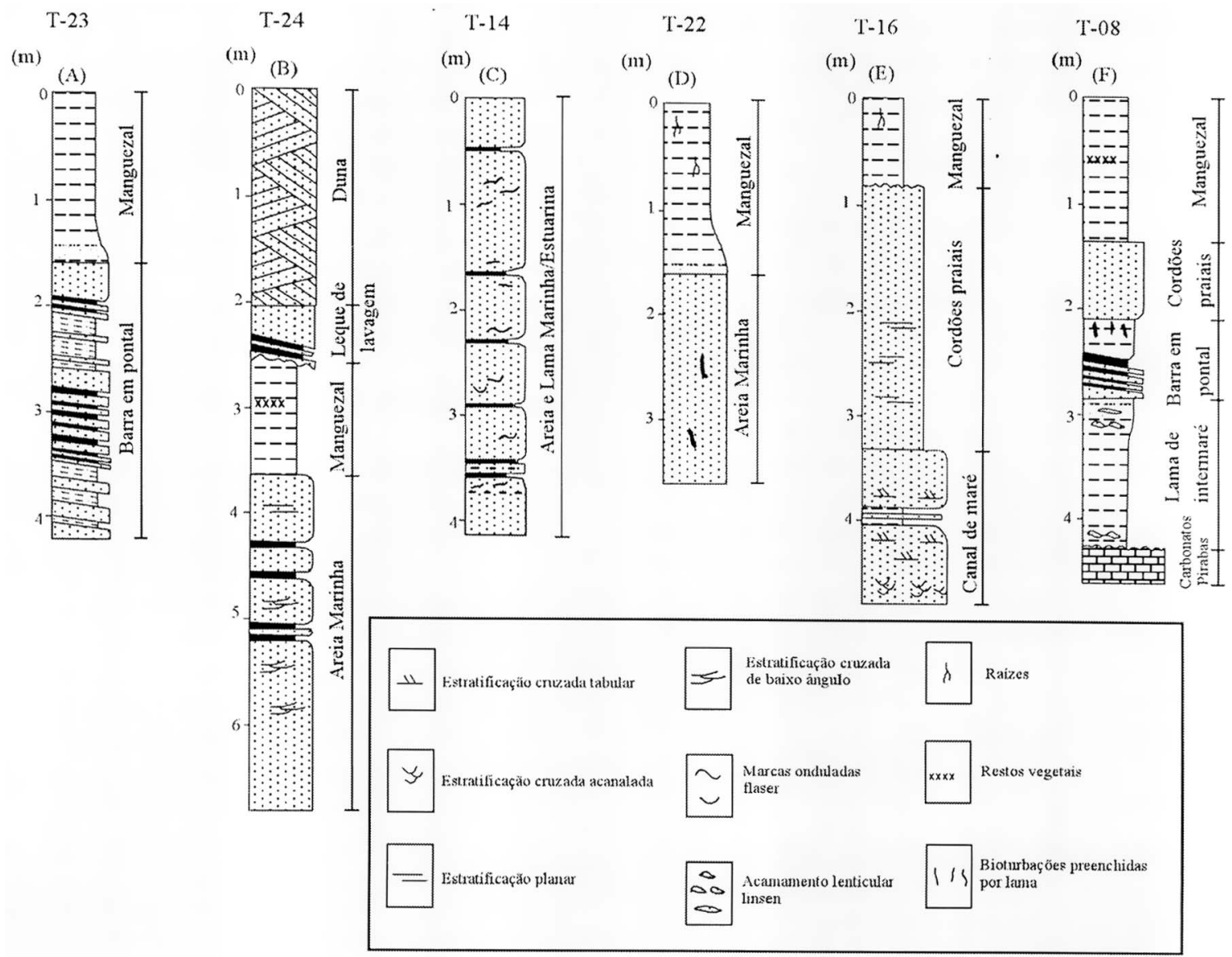

Fig. 2. Seções estratigráficas ilustrando as principais unidades morfológicas e fácies estratigráficas que ocorrem no NW da Planície Costeira de São João de Pirabas. 


\section{Fácies areia e lama de barra em pontal}

Encontra-se interdigitada com a fácies Lama de Intermarés ( $\mathrm{T}-08)$ e possui uma espessura de $70, \mathrm{~cm}$. É constituída, na base, por camadas e níveis de areia fina a muito fina, angulosa a subangulosa, bem selecionada, de coloração cinza claro (N7) a cinza claro médio (N6), com espessura que alcança $5 \mathrm{~cm}$, intercaladas com níveis lamosos, milimétricos, de coloração cinza médio (N5) ("mud drapes") que constituem a estratificação heterolítica inclinada. Para o topo, a sequiência torna-se mais lamosa e encontra-se intensamente bioturbada (Fig. 2F).

\section{Fácies lama de intermaré}

Esta fácies está distribuída sob a fácies Areia de Cordões Praiais (T-03, T04, T-08, e T-10) em contato erosivo, a uma profundidade que varia de 60 a $240 \mathrm{~cm}$ e uma espessura total em torno de $330 \mathrm{~cm}$. É constituída por sedimentos lamosos de coloração cinza amarronzado claro (5 YR 6/1), com perfuraç̃oses, que persistem até os $200 \mathrm{~cm}$ de profundidade, preenchidas por areia muito fina e/ou silte de coloração cinza claro (N7). A partir dos 175 $\mathrm{cm}$, esta seqüência lamosa adquire uma coloração cinza escuro médio (N4), com intercalações de areia muito fina e/ou silte de coloração cinza claro (N7) que definem um acamamento lenticular, muitas vezes interligados, com lentes espessas que alcançam os 3 $\mathrm{cm}$ e lentes delgadas de dimensões milimétricas. Essas estruturas ocorrem em toda a seqüência e são características de ambiente de planície de intermarés lamosa (Fig. 2F).

\section{Fácies sedimentos argilo-arenosos}

Esta fácies ocorre sob os sedimentos lamosos da Unidade Morfoestratigráfica Manguezal (Fig. 3). Trata-se de sedimentos argilosos, argiloarenosos e arenosos, maciços, por vezes contendo clastos de argila de pequenas dimensões (menores que $2 \mathrm{~cm}$ ). Apresentam coloração cinza muito claro (N8) a cinza médio (N5), com tonalidades amarelo moderado (5 Y 7/6) e marrom claro (5 YR 5/6), conferindo a esta fácies um padrão mosqueado. Esta fácies é relacionada aos sedimentos do Grupo Barreiras e corresponde às fácies argilosa maciça e arenosa sem estruturação aparente (Rossetti et al., 1989).

\section{Fácies Sedimentos Carbonáticos}

Ocorre na base do testemunho T-08 a 420 $\mathrm{cm}$ de profundidade (Fig. 2F), sob os sedimentos lamosos da fácies Lama de Manguezal. Está representada por sedimentos argilo-arenosos carbonáticos, maciços e fossilíferos, contendo grãos de quartzo dispersos, relacionados aos carbonatos da Formação Pirabas. Apresentam coloração cinza claro médio (N6) a cinza escuro médio (N4), com tonalidades marrom amarelado moderado (10 YR

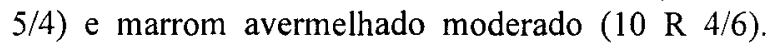
Esta fácies juntamente com a fácies Argilo-Arenosa compõe o embasamento da área estudada .

\section{Sucessões estratigráficas}

A correlação lateral e vertical das diversas unidades e fácies descritas anteriormente, revelou um padrão de sedimentação na área, que pode ser entendido através de quatro sucessões marinhas distintas: (a) Sucessão Marinha Retrogradacional Basal (SB); (b) Sucessão Marinha Retrogradacional (S1); (c) Sucessão Marinha Progradacional (S2) e; (d) Sucessão Atual (S3), cada uma com seus respectivos ambientes e subambientes deposicionais característicos (Figs 3 e 4).

A Sucessão Marinha Retrogradacional Basal (SB), está representada pelas fácies Lama de Intermarés, com seus depósitos de barras em pontal, disposta lateralmente a areias de Canal de Maré. Sobrepostas a essas fácies, ocorrem areias de Cordões Praiais, por vezes associadas com areias de Paleodunas. Esta sucessão ocorre desde a superfície (Sistema de Terraços) até a profundidade de $5,7 \mathrm{~m}$, alcançando uma espessura total de $9 \mathrm{~m}$, representando, respectivamente, ambientes de planície de maré e litorâneo.

Os sedimentos da Fácies Lama de Intermarés ocorrem na base da sucessão e estão distribuídos desde o sudeste (Pilões) até o centro da Ilha de Itarana, em uma profundidade que varia de 0,6 a 2,6 $\mathrm{m}$. Sua deposição estaria relacionada a antigos furos e córregos de maré, protegidos da influência de ondas e correntes, semelhantes aos encontrados atualmente. Estes antigos furos e córregos, estavam associados às exposições dos calcários Pirabas, (Testemunho $\Upsilon-08$ - Fig. 2F) e ocorriam ainda, atrás de antigos cordões praiais recobertos por paleodunas.

A migração dos cordões praiais sobre os depósitos lamosos, evidenciou um contato erosivo, onde pode ser observados clastos argilosos retrabalhados em meio aos sedimentos arenosos sobrejacentes. A observação de estruturas primárias perturbadas por perfurações de organismos, e a coloração cinza amarronzado claro evidenciam um período de exposição e/ou sob uma fina lâmina d'água, antes de serem recobertos pelos sedimentos da Fácies Areias de Cordões Praiais. 

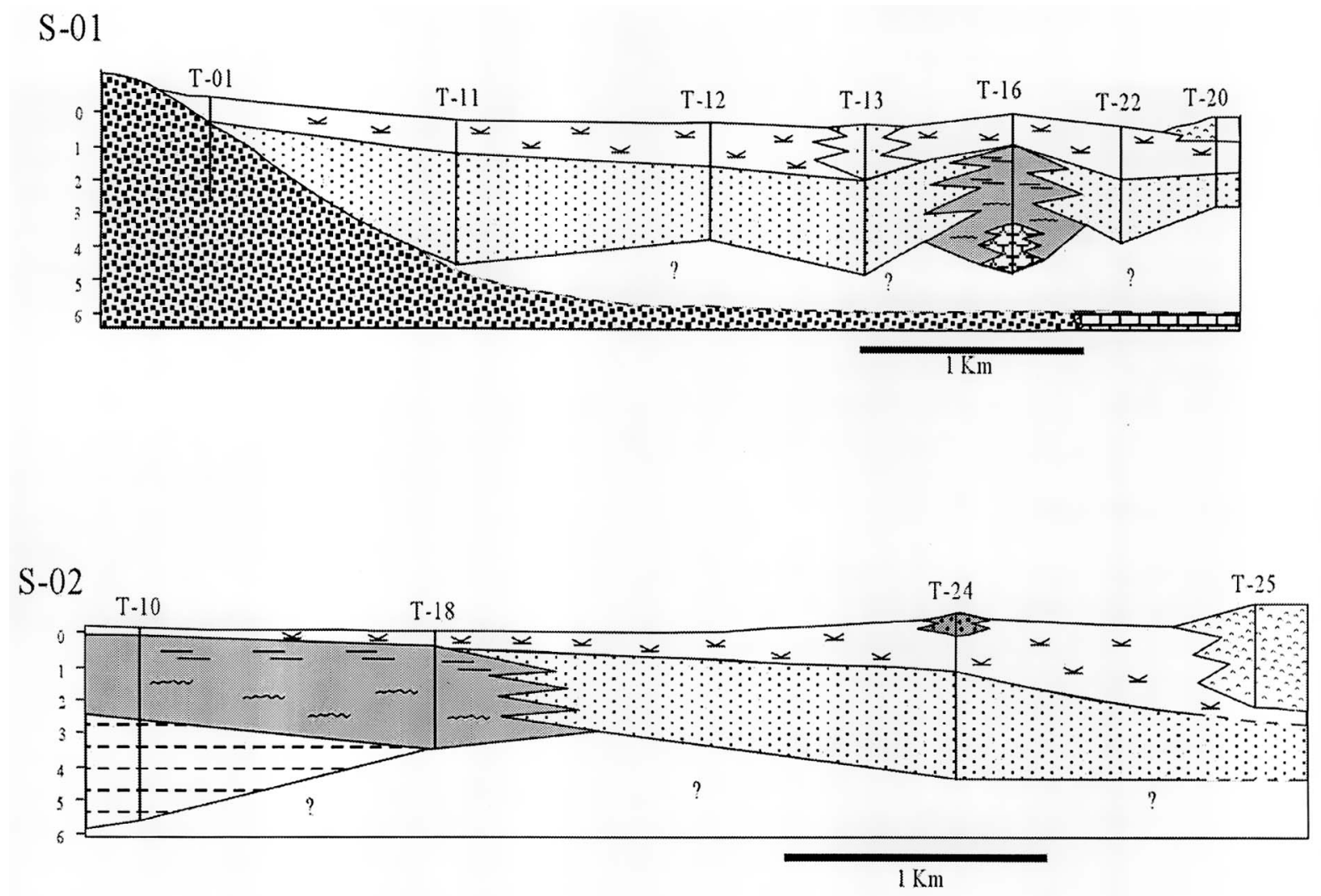

\section{LEGENDA}

Grupo Barreiras Formação Pirabas Sucessão Marinha Retrogradacional (S1)

59 Areia e Lama Marinha/Estuarina

Sucessão Marinha Retrogradacional Basal (SB)

Sucessão Marinha Progradacional (S2)

Areia de Cordões Praiais

$\approx$ Manguezal

[-] Lama de Intermaré

10. Chênier

조족 Areia de Canal de Maré

Sucessão Atual (S3)

Cordões duna-praia atuais

$\because$ Barras arenosas

Fig. 3. Seções estratigráficas ilustrando as sucessões SB, S1, S2 e S3. 


\begin{tabular}{|c|c|c|c|c|c|c|}
\hline $\begin{array}{l}E \\
R \\
A\end{array}$ & $\begin{array}{l}P \\
E \\
R \\
i \\
O \\
D \\
O\end{array}$ & $\begin{array}{l}\text { E } \\
P \\
O \\
C \\
A\end{array}$ & & UNIDADES & AMBIENTES & $\begin{array}{c}\text { SUCESSÕES } \\
\text { ESTRATIGRÁFICAS }\end{array}$ \\
\hline $\begin{array}{l}C \\
E\end{array}$ & $\begin{array}{l}Q \\
U\end{array}$ & $\begin{array}{l}\mathrm{H} \\
\mathrm{O} \\
\mathrm{L}\end{array}$ & 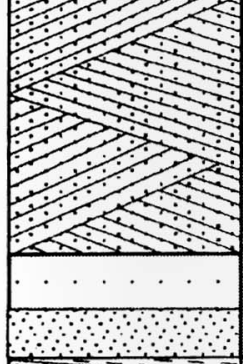 & $\begin{array}{l}\text { Dunas } \\
\text { Frontais } \\
\text { (Atuais) } \\
\text { Praia } \\
\text { Barras } \\
\text { Arenosas } \\
\end{array}$ & Litorâneo & Sucessão Atual (S3) \\
\hline $\begin{array}{l}N \\
0\end{array}$ & $\begin{array}{l}\mathrm{A} \\
\mathrm{T} \\
\mathrm{E} \\
\mathrm{R}\end{array}$ & $\begin{array}{l}O \\
C \\
E \\
N\end{array}$ & 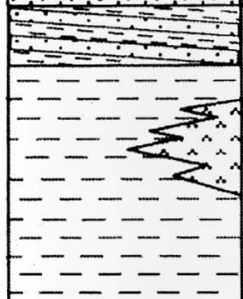 & $\begin{array}{c}\text { Barra em } \\
\text { Pontal } \\
\text { Chenier } \\
\text { Manguezal }\end{array}$ & $\begin{array}{l}\text { Planicie de } \\
\text { Maré }\end{array}$ & $\begin{array}{c}\text { Sucessão Marinha } \\
\text { Progradacional } \\
\text { (S2) }\end{array}$ \\
\hline Ó & $\begin{array}{l}\text { A } \\
\text { R }\end{array}$ & 0 & & Face Praial & Litorâneo & $\begin{array}{c}\text { Sucessão Marinha } \\
\text { Retrogradacional } \\
\text { (S1) }\end{array}$ \\
\hline \multirow[t]{3}{*}{0} & $\mathrm{O}$ & $\begin{array}{l}P \\
L \\
E \\
\text { I } \\
\text { S } \\
T \\
O \\
C \\
E \\
N \\
O\end{array}$ & 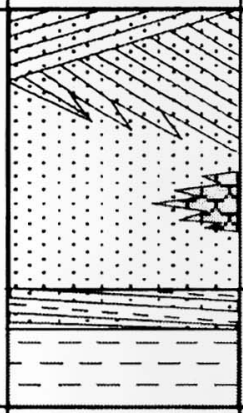 & \begin{tabular}{|l} 
Paleodunas \\
Canal de Maré \\
Cordões Praiais \\
Barra em \\
Pontal \\
Manguezal \\
\end{tabular} & $\begin{array}{c}\text { Planicie de } \\
\text { Maré }\end{array}$ & $\begin{array}{c}\text { Sucessão Marinha } \\
\text { Retrogradacional } \\
\text { (SB) }\end{array}$ \\
\hline & & & $?$ & $?$ & $?$ & $?$ \\
\hline & & $\begin{array}{l} \\
E \\
R \\
C \\
1 \\
\dot{A} \\
R \\
1 \\
O\end{array}$ & 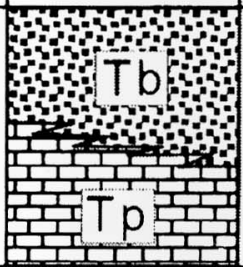 & $\begin{array}{c}\text { Grupo } \\
\text { Barreiras } \\
\text { Formação } \\
\text { Pirabas }\end{array}$ & $\begin{array}{l}\text { Planicie de } \\
\text { Maré } \\
\text { Plataformal } \\
\text { Raso }\end{array}$ & \\
\hline
\end{tabular}

Fig. 4. Coluna estratigráfica simplificada para o noroeste da Planícic Costeira de São João de Pirabas. 
Os depósitos arenosos da Fácies Areia de Cordões Praiais, são amplamente distribuidos na Ilha de Itarana, estando dispostos na forma de terraços. Na localidade de Pilões (SE da Ilha de Itarana), estes depósitos ocorrem a cerca de $1,5 \mathrm{~m}$ acima do nível de maré alta atual, e são observados também durante a maré baixa em outras áreas. Nesses sedimentos, são observadas estratificações cruzadas de baixo ângulo, plano-paralelas e marcas onduladas, que caracterizam um ambiente típico de praia. Estes sedimentos apresentam-se com coloração marrom escuro, função da concentração de ácidos húmicos e óxidos e hidróxidos de ferro.

Associados aos antigos cordões praiais, ocorrem sedimentos arenosos distribuídos principalmente a NW da Ilha de Itarana, relacionados a antigos canais de maré (Fácies Areia de Canal de Maré) que recortavam, parcialmente, os sedimentos praiais.

A Sucessão Marinha Retrogradacional (S1) está distribuída a uma profundidade de 1,5 a $4,5 \mathrm{~m}$, sendo constituída pelas Fácies Areia e Lama Marinha/Estuarina e Areia Marinha, de ambiente litorâneo.

A formação desta sucessão, ocorreu sob condições transgressivas, marcada pela deposição de sedimentos de ambiente praial de águas rasas (Fácies Areia Marinha e Areia e Lama Marinha/Estuarina), evidenciadas pela presença de estruturas como marcas onduladas, acamamento de maré e flaser. Nesta sucessão, foi encontrado, associada à Fácies Areia e Lama Marinha/Estuarina, um nivel de concentração de conchas marinhas (águas rasas) evidenciando um provável nível de mar transgressivo de $-3 \mathrm{~m}$, durante a formação desta sucessão.

A Sucessão Marinha Progradacional (S2) corresponde a sedimentos predominantemente lamosos, depositados em condições regressivas ou de nível de mar estável. São caracterizados por depósitos de manguezais, resultado de uma sedimentação em áreas com águas pouco agitadas e durante o estofo das marés; e por barras em pontal, geradas a partil da migração lateral de canais de maré. Ocorrem ainda, sedimentos arenosos representativos de cordões dunapraia, com leques de lavagem associados ("cheniers"), dispostos em meio aos depósitos de manguezal, originados durante fases erosivas que retrabalharam os sedimentos costeiros, permitindo a formação destes cordões.

Os depósitos atuais estão representados por praias, dunas e barras arenosas longitudinais e barras de baía, que estão sob a influência de ondas e correntes de maré e de deriva litorânea. Estes ambientes compõem a Sucessão Atual (S3) que migra em direção ao continente, soterrando os depósitos da Unidade Morfoestratigráfica Manguezal.
As sucessões marinhas holocênicas S1, S2 e S3, são respectivamente correlacionáveis (cronologicamente) às Seqüências Transgressiva Basal (S1), Regressiva (S2) e Transgressiva Atual (S3), definidas por Souza Filho (1995) na Planície Costeira Bragantina, cuja deposição iniciou em torno de 5.100 anos A P. A Sucessão Retrogradacional Basal SB, corresponderia a uma fase mais antiga de deposição, que ocorreu provavelmente durante $o$ Pleistoceno Terminal (?).

\section{Discussão e conclusões}

Registros de oscilações do nível do mar durante o Quaternário em planícies costeiras brasileiras, foram bem caracterizados sobretudo nos litorais leste e sul do Brasil. Estes setores, dispõem de várias datações absolutas que permitiram a elaboração de curvas de variação do nivel do mar, principalmente nos últimos 6.000 anos A.P. Para a região Norte, ainda não foi definida nenhuma curva de variação do nível do mar em função da falta de datações absolutas. Os dados existentes até o momento, confirmam a existência de paleoníveis marinhos a $-20,-40$ e $-80 \mathrm{~m}$ na Plataforma Continental do Amazonas (El-Robrini \& Souza Filho, 1994; El-Robrini, 1997).

Segundo Curray (1965, apud Macintyre et al., 1978), o nível do mar nas plataformas continentais do mundo, há cerca de 29.000 anos A.P., estava situado a aproximadamente $-10 \mathrm{~m}$ passando a sofrer uma diminuição que alcançou uma profundidade em torno de $-120 \mathrm{~m}$ há cerca de 19.000 anos A. P., voltando a subir, a partir de então, até o nivel atual.

Kowsmann \& Costa (1974) definiram três níveis de permanência da linha de costa durante o Quaternário na Plataforma Continental Norte. O primeiro se desenvolve entre a costa e a isóbata de $50 \mathrm{~m}$; o segundo é expresso por um pico duplo, com um pico predominante localizado a $-90 \mathrm{~m}$ e um pico menor localizado a $-110 \mathrm{~m}$; e o terceiro está localizado na região da isóbata de $-170 \mathrm{~m}$. Consideraram ainda, que na hipótese de ter havido subsidência na ordem de $3 \mathrm{~m}$ a cada 1.000 anos durante os últimos 18.000 anos seria atribuída essa idade ao nível de $-170 \mathrm{~m}$ e 16.000 anos ao nível de $110 \mathrm{~m}$. Por outro lado consideraram também a possibilidade de uma pequena subsidência, datando o nível de $-170 \mathrm{~m}$ em 40.000 anos e o nível de $-110 \mathrm{~m}$ com idade de 18.000 anos.

Millimann \& Barreto (1975) descreveram para a Plataforma Continental do Amazonas, que há cerca de 17.400 anos A. P. o nível do mar estava a 
uma profundidade em torno de $-80 /-90 \mathrm{~m}$ em relação ao nivel atual.

Na porção NW da Planície Costeira de São João de Pirabas, a falta de controle do comportamento do nível do mar em função da ausência de datações, impõem limitações nas considerações sobre os aspectos evolutivos responsáveis pela formação das principais feições morfológicas e dos depósitos quaternários (holocênicos e provavelmente pleistocênicos) desta planície. Porém, a partir das características deposicionais das diversas unidades e fácies estratigráficas e resgatando as informações disponíveis na literatura referente a antigos níveis marinhos na Plataforma Continental do Amazonas, é apresentada uma ordenação cronológica dos principais eventos deposicionais e erosivos que atuaram na área, em resposta principalmente, às possíveis oscilações do nível do mar que atuaram desde o Pleistoceno Terminal. Tais considerações foram baseadas na curva de variação do nível do mar descrita por Curray (1965, apud Macintyre et al., 1978) além dos trabalhos de Kowsmann \& Costa (1974) e Millimann \& Barreto (1975). Aliadas a essas variações, movimentos neotectônicos atuantes desde o Plioceno também merecem destaque.

As principais estruturas neotectônicas reconhecidas na região, compreendem segundo Costa et al. (1992), dois conjuntos principais. O primeiro refere-se a falhas normais NW-SE e falhas transcorrentes E-W, e o segundo, corresponde essencialmente a falhas transcorrentes NE-SW. Dentre estes, destacam-se os lineamentos NW-SE, por serem os mais expressivos, controlam em parte o sistema de drenagem, promovendo basculamentos nos pacotes sedimentares da Formação Pirabas e do Grupo Barreiras, e correspondem a falhas normais fortemente inclinadas para NE.

$O$ arranjo dessas estruturas proporcionou a formação de uma paleotopografia que teve um papel determinante na distribuição e espessura dos sedimentos (fácies e ambientes) quaternários.

Os sedimentos da Sucessão Marinha Retrogradacional Basal (SB), possuem características sedimentológicas que indicam a influência de condições transgressivas que são, tentativamente, consideradas como sendo instaladas no final do Pleistoceno, em torno de 29.000 anos A.P., (Curray 1965, apud Macintyre et al., 1978), onde o nível do mar nesta época, provavelmente atingiu elevações em torno do nível atual. Este evento, permitiu inicialmente, a deposição de barras pré-litorais edificadas sobre os carbonatos da Formação Pirabas e adjacentes ao Planalto Costeiro. Posteriormente, essas barras evoluíram para um sistema de cordões dunapraia que funcionava como uma barreira, permitindo deste modo, a deposição de sedimentos lamosos, dispostos lateralmente aos cordões, em áreas protegidas da ação de ondas e correntes.

A partir da descida do nível do mar, que alcançou uma profundidade em torno de $-80 /-90 \mathrm{~m}$, na Plataforma Continental do Amazonas, há cerca de 17.400 anos A.P. (Milliman \& Barreto, 1975), estes sedimentos ficaram expostos, gerando um sistema de terraços que passaram a sofrer influências de fortes processos pedogenéticos.

A ocorrência de sedimentos arenosos de coloração avermelhada e marrom escuro, cimentados por matéria orgânica e hidróxidos de ferro e sob forte processo pedogenético (solo do tipo podzol) foram descritos por Muehe \& Corrêa (1988) nas praias de Itaipuaçu e Guaratiba (Rio de Janeiro), sendo sua idade considerada superior aos sedimentos do cordão holocênico mais antigo definido nesta região.

Nas regiões de Cananéia (SP) e Paranaguá (PR), sedimentos arenosos ricos em matéria orgânica endurecidas epigeneticamente, também foram considerados de idade pleistocênica por Suguio et al. (1985) e Martin et al. (1988 apud Angulo \& Lessa, 1997), apesar de Angulo \& Lessa (1997), em uma reavaliação das curvas propostas para estas regiões, considerarem que estes sedimentos também podem ocorrer no Holoceno.

$O$ registro de Sambaquis de idade em torno de 5.200 anos A. P. (Simões, 1981) associados às paleodunas e à porção superior dos sedimentos da Fácies Lama de Intermaré, levam a crer que esta sucessão, já existia quando os antigos habitantes deste trecho do litoral paraense começaram sua instalação nestas áreas.

Desta forma, a correlação dos sedimentos da Sucessão SB com sedimentos semelhantes encontrados, principalmente nas costas sudeste e sul do Brasil, foi o único argumento para considerar a idade desta sucessão. Apesar das características sedimentológicas semelhantes, considerações mais precisas sobre a idade da Sucessão SB, necessitariam ser complementadas por datações, o que forneceria dados mais concretos sobre em que época a deposição destes sedimentos teria acontecido.

Com a subida do nível do mar a partir de 19.000 anos A. P., (Curray 1965, apud Macintyre et al., 1978), provavelmente houve a instalação de condições transgressivas nas plataformas continentais do mundo. Nestas condições, a área estudada teria sido afetada, causando inicialmente, a deposição de sedimentos arenosos e lamosos da Fácies Areia e Lama Marinha/Estuarina. Estes sedimentos formavam uma planície arenosa com barras de baía estuarinas na porção proximal do sistema deposicional, enquanto os sedimentos praiais da Fácies Areia Marinha correspondiam à porção distal do sistema. 
A contínua subida do nível do mar, provocou a migração destas fácies em direção ao continente, erodindo o Planalto Costeiro e o sistema de terraços, dando origem assim à Sucessão Retrogradacional (S1). Associados aos sedimentos da Fácies Areia e Lama Marinha/Estuarina, foram encontrados a $-3 \mathrm{~m}$, níveis de concentração de conchas (T-11) características de águas rasas, evidenciando um antigo nível marinho naquela profundidade.

Alcançado o nível máximo durante a Transgressão Holocênica (5.100 anos A.P), provavelmente ocorreu, em condições de mar estável, a formação dos depósitos lamosos de manguezal, que deu origem a uma frente de progradação em direção ao mar. Associados a essa progradação, eventos erosivos retrabalharam os sedimentos costeiros originando cordões duna-praia.

Posteriormente, com o restabelecimento das condições progradantes, estes cordões foram isolados pelos manguezais dando origem aos cheniers.

Atualmente, os sedimentos lamosos de manguezal, em alguns locais da área, estão sendo recobertos por cordões arenosos (Sucessão Atual S3) que migram em direção a esses depósitos superpondo-se aos mesmos.

A partir dos dados apresentados anteriormente, pode-se considerar que o modelo deposicional atual da Planície Costeira de São João de Pirabas, pode ser entendido como uma planície costeira dominada por macro-marés semi-diurnas, com sistemas de terraços marinhos, sobrepostos por cordões arenosos e sedimentos lamosos progradantes.

A evolução da área estudada tomou como base apenas a descrição das características dos sedimentos e associação destes em sucessões estratigráficas, as quais foram correlacionadas às prováveis variações do nível do mar. Ressalta-se ainda, a influência das estruturas neotectônicas que desempenharam um papel determinante na edificação de uma paleotopografia sobre a qual estão os depósitos recentes. Trabalhos futuros objetivando datações são de fundamental importância na definição de oscilações do nível do mar, dando deste modo, um maior suporte as considerações aqui descritas e uma melhor definição dos eventos que atuaram na região.

\section{Referências bibliográficas}

Angulo, J. R \& Lessa, G. C. 1997. The Brazilian sealevel curves: A critical review with emphasis on the curves from the Paranaguá and Cananéia regions. Mar. Geol., 140(1-2):141-166.
Arai, M.; Uesugui, N.; Rossetti, D. F. \& Góes, A. M. 1988. Considerações sobre a idade do Grupo Barreiras no Nordeste do Estado do Pará. In: CONGRESSO BRASILEIRO DE GEOLOGIA, 35. Belém, 1988. Anais. Belém, SBG, 2:738-752.

Augustinus, P. G. E. F. 1989. Cheniers and cheniers plains: a general introduction. Mar. Geol., 90(4):219-229.

Costa, J. B. S.; Borges, M. S.; Bemerguy, R. L.; Fernandes, J. M. G.; Costa Junior, P. S. \& Costa, M. L. 1992. Geologia (Folha Salinópolis). Relatório Técnico/91. Tema 4. Belém, IBAMA/SECTAM/IDESP. p.18-58.

DHN - Diretoria de Hidrografia e Navegação. 1998. Tábuas de marés para 1999. Costa do Brasil e alguns portos estrangeiros. 33a ed. Rio de Janeiro, DHN. p. 1-6.

DHN - Diretoria de Hidrografia e Navegação. 1986. Roteiro da Costa Norte. Rio de Janeiro, DHN. $152 \mathrm{p}$.

El-Robrini, M \& Costa, P. S. J. 1993. Considerações sobre a dinâmica costeira no NE do Pará. In: $11^{\text {a }}$ SEMANA DE SEMINÁRIOS DE PÓSGRADUAÇÃO EM GEOLOGIA E GEOQUÍMICA. 11. Belém, 1993. p. 39-41.

El-Robrini, M. 1993. Batimetria-sedimentologiahidrodinâmica e parâmetros físico-químicos das águas. Projeto oceanográfico da Folha Marapanim (SA-23-V-A-VI). Belém, IDESP. Relatório Final. $16 \mathrm{p}$.

El-Robrini, M. 1997. Contribuition to the recognition of the Paleo Corals Upper Quaternary on the Amazor Break Slope. Workshop OSNLR - IOCARBE. 17p.

El-Robrini, M. \& Souza Filho, P. W. M. 1994. A plataforma continental do Amazonas e as evidências das oscilações do nível do mar durante o quaternáric superior terminal. In: CONGRESSO BRASILEIRC DE GEOLOGIA, 38. Camboriú, 1994. Anais Camboriú, SBG, 1:417-419.

Faria Jr., L. E. C.; El-Robrini, M.; Torres, A.; Leandro A.; Silva, C. A.; Souza Filho, P. W. M. \& Costa, W P. 1992. Batimetria. In: PROGRAMA NACIONAL DE GERENCIAMENTO COSTEIRO MACROZONEAMENTO COSTEIRO DC ESTADO DO PARÁ. Relatório Final, Belém IBAMA/SECTAM/IDESP. p. 8-16. 
Ferreira, C. S. \& Cunha, O. R. 1957. Notas sobre a Formação Pirabas com descrição de novos invertebrados fósseis I (Mollusca-Gastrópoda). Bol. Mus. Para. Emilio Goeldi, sér. Ciênc. da Terra, 2:1-61.

Ferreira, C. S. \& Cunha, O. R. 1959. Contribuição à Paleontologia do Estado do Pará. Novos invertebrados fósseis e redescrição de mais duas espécies da Formação Pirabas, III (MolluscaGastrópoda). Bol. Mus. Para. Emilio Goeldi, sér. Ciênc. da Terra, 4:1-33.

Ferreira, C. S. 1980. Correlação da Formação Pirabas (Mioceno Inferior) $\mathrm{N}$ e $\mathrm{NE}$ do Brasil com as formações Chipola e Tampa da Península da Flórida - USA. In: CONGRESSO LATINO AMERICANO DE GEOLOGIA 1. Buenos Aires, 1980. Atas. Buenos Aries, APA, 3:49-55.

Francisco, B. H. R.; Loweenstein, P. \& Silva, G. G. 1971. Contribuição à geologia da Folha de São Luís (SA-23), no Estado do Pará. Bol. Mus. Pará. Emilio Goeldi, sér. Ciênc. da Terra, 17:1-45.

Franzinelli, E. 1982. Contribuição a geologia da costa do Estado do Pará (entre a Baía de Curuçá e Maiaú). In: SIMPÓSIO DO QUATERNÁRIO DO BRASIL, 4. Rio de Janeiro. 1982. Atas. Rio de Janeiro, CENPES-PETROBRAS. p. 305-322.

Franzinelli, E. 1990. Evolution of the geomorfology of the coastal of the state of Pará, Brasil. In: SYMPOSIUM PICG 274. Cayene, 1990. Anais. Cayene, ORSTOM. p. 203-230.

Frey, J. C. \& Milliman, H. B. 1960. Classification of the Wisconsinian stage in the Lake Michigan glacial lobe. Illinois State Geological Survey, 285:1-16.

IDESP - Instituto do Desenvolvimento EconômicoSocial do Pará. 1992. Programa Nacional de Gerenciamento Costeiro. Macrozoneamento Costeiro do Estado do Pará. Belém, IBAMA/SECTAM/IDESP. Relatório Final. 167p.

Kowsmann, O. R. \& Costa, M. P. A. 1974 . Paleolinhas de costa na plataforma continental das regiões sul e norte brasileira. Revista Brasileira de Geociências, 4:215-222.

Macintyre, I. G.; Pilkey, O. H. \& Stuckenrath, R. 1978. Relict oysters on the United States Atlantic continental shel: A reconsideration of their usefulness in understanding late Quaternary sealevel history. Geological Society of America Bulletin, v.89, p.277-282.
Martorano, L. G.; Pereira, L. C.; Cezar, E. G. M. \& Pereira, I. C. B. 1993. Estudos climáticos do Estado do Pará, classificação climática (Köppen) e deficiência hídrica (Thornthwhite, Matter). Belém, SUDAM/EMBRAPA, SNLCS. 53p.

Maury, C. J. 1925. Fósseis terciários do Brasil. Serviço Geológico Mineralógico do Brasil. Monografia no 4. p. 4-35.

Milliman, J. D. \& Barreto, H. T. 1975. Relict magnesian calcite oolite and subsidence of Amazon shelf. Sedimentology, 22:137-145.

Muehe, D. \& Corrêa, H. T. 1988. Os arenitos de restinga do cordão litorâneo da Maçambaba/Lagoa de Araruama-RJ. In: CONGRESSO BRASILEIRO DE GEOLOGIA, 35. Belém, 1988. Anais. Belém, SBG, 2:553557.

Pereira, S. W. M. 1994. Mapeamento planialtimétrico e morfotopográfico da micro-região do Salgado Paraense a partir de procedimentos fotogramétricos. M.Sc. thesis. Belém, Universidade Federal do Pará. 126p.

Rhodes, E. G. 1982. Depositional model for a chênier plain, Gulf Carpentaria, Austrália. Sedimentology, 29:1-19.

Rossetti, D. F.; Truckenbrodt, W. \& Góes, A. M. 1989. Estudo paleoambiental e estratigráfico dos sedimentos Barreiras e pós-Barreiras na região Bragantina, Nordeste do Pará. Bol. Museu Para. Emílio Goeldi, ser. Ciências da Terra, 1(1):2574.

Santos, V. F. 1996. Estratigrafia holocênica e morfodinâmica atual da planície costeira da Ilha de Algodoal e Marudá. M.Sc. thesis. Belém, Universidade Federal do Pará.

Senna, C. S. F.; Bastos, M. N. C.; Oliveira, J. R.; Lobato, L. C.; Santos, R. T. \& Moraes, P. G. 1992. In: PROGRAMA NACIONAL DE GERENCIAMENTO COSTEIRO. MACROZONEAMENTO COSTEIRO DO ESTADO DO PARÁ. Geomorfologia. Belém, IBAMA/SECTAM/IDESP. p. 60-66.

Schaeffer-Novelli. Y. 1989. Perfil dos ecossistemas litorâneos brasileiros, com especial ênfase sobre o ecossistema manguezal. Publção esp. Inst. oceanogr., S Paulo, (7):1-16. 
Silva Júnior, O. G. 1998. Morfoestratigrafia da planície costeira de São João de Pirabas (porção NW) - NE do Estado do Pará. M.Sc. thesis. Belém, Universidade Federal do Pará. 87p.

Silva Júnior, O. G. \& Soares, C. M. 1992. Mapeamento do Município de São João de Pirabas, NE do Estado do Pará. Belém, Universidade Federal do Pará, Departamento de Geologia. Relatório 179p.

Silva, C. A. 1998. Análise morfoestratigráfica dos depósitos estuarinos do Rio Marapanim - Nordeste do Pará. M.Sc. thesis. Belém, Universidade Federal do Pará. 142p.

Silva, M. S. 1996. Morfoestratigrafia e evolução da planície costeira de Salinópolis. NE do Estado do Pará. M.Sc. thesis. Belém, Universidade Federal do Pará. 142p.

Simões, M. F. 1981. Pescadores-coletores ceramistas do litoral do Salgado (Pará). Bol. Mus. Pará. Emilio Goeldi, nova sér. Antropologia, 78:1-33.

Souza Filho, P. W. M. 1995. A planície costeira Bragantina (NE do Pará): influências das variações do nível do mar na morfoestratigrafia costeira durante o Holoceno. M.Sc. thesis. Belém, Universidade Federal do Pará. 121p.
Suguio, K.; Martin, L.; Bittencourt, A. C. S. P.; Dominguez, J. M. L.; Flexor, J. \& Azevedo, A. E. G. 1985. Flutuações do nível relativo do mar durante o Quaternário Superior ao longo do litoral brasileiro e suas implicações na sedimentação costeira. Revista Brasileira de Geociências, 15(4):273-286.

Woodroffe, C. D.; Chapell, J.; Thom, B. G. \& Wallensky, E. 1986. Geomorphological dinamics and evolution of the South Alligator River and plains, Northern Territory. Austrália National University. North Austrália Research Unit. Mangrove Monograph n 3. 190p.

Woodroffe, C. D.; Chapell, J.; Thom, B. G. \& Wallensky, E. 1989. Depositional of a macrotidal estuary and flood plain, South Alligator River, Northern Australia. Sedimentology, 36(5):737-756.

(Manuscrito recebido 09 março 2000; revisado 29 março 2001; aceito 21 março 2002) 